\title{
Seismic behavior of a precast hollow core wall under biaxial lateral cyclic loading
}

\author{
N. H. Hamid \& K. D. Ghani \\ Faculty of Civil Engineering, Universiti Teknologi Mara, Malaysia
}

\begin{abstract}
The seismic performance of two geometrically similar precast concrete hollow core walls are investigated experimentally under biaxial lateral cyclic loading. Two wall specimens are detailed with steel-armouring at their base-to-foundation interfaces including supplementary unbonded post-tensioned prestress, fuse-bars and mechanical energy dissipators. Wall 1 , with a fixed location of bonded fusebars and unbonded tendons, is tested under various biaxial load paths including "4-leaf clover" and "double 4-leaf clover" patterns. Wall 2 is similarly tested with two different configurations of unbonded tendons, unbonded fuse-bars and steel mechanical energy dissipators. A shaking table is used in slow motion to perform the reversed cyclic in-plane and out-of-plane bi-lateral quasi-static experiments. Test results show that both walls perform very well under various load paths without any discernible structural damage up to $2.0 \%$ wall drifts. It is concluded that for initial design equivalent viscous damping of $10 \%$ may be adopted to accommodate the effects of hysteretic behaviour.

Keywords: bi-lateral loading, steel-armouring, fuse-bars, unbonded posttensioned tendons, equivalent viscous damping, mechanical energy dissipators.
\end{abstract}

\section{Introduction}

Historically, the principal criterion in designing seismic resistant buildings is to maintain life-safety of the structure even though some damage is permitted. Fintel [1] concluded that based on 30 years of evidence, reinforced concrete buildings with structural walls performed well in earthquakes. However, on the contrary, evidence from past earthquakes [2-6] show that precast concrete wall buildings did not perform very well, particularly at connections and junctions with other structural components. And although many buildings did perform 
sufficiently well to ensure that life-safety was preserved, substantial damage to the walls in many buildings led to loss of amenity including major business interruption.

The principal subject of this paper is to present experimental findings of precast prestressed walls that are free to rock on their foundations and to demonstrate the viability of using a Damage Avoidance Design philosophy when applied to rocking precast hollow core wall panels. Rocking structures are not a new phenomenon. An early study by Housner [7] defined the behaviour of a rigid rocking body under earthquake excitation. Further investigations were carried out by Meek [8] and Yim et al. [9] who considered the aspects of structural flexibility and slenderness ratio of rocking structures. In addition to the above attributes, Aslam et al. [10] investigated the response of rigid rocking bodies that were vertically prestressed to the foundation. Subsequently, Priestley and MacRae [11] experimentally demonstrated that as well as providing moment resistance at the connection, the clamping force supplemented by prestressing of the tendons could adequately resist the shear demand at the rocking beamcolumn joint interface.

This research investigates the viability of a Damage Avoidance Design (DAD) philosophy applied to a class of single storey industrial buildings where the walls are constructed using multiple precast prestressed concrete hollow core panels. The objective is to explore the seismic performance of a single precast hollow core wall unit under bi-directional lateral loading including the effects of gravity load. This study also aims to investigate the efficacy of different classes of internal and external mechanical energy dissipation devices along with different levels of initial supplementary unbonded post-tensioned prestress steel. Recommendations relate practical solutions amenable to rapid construction with optimal seismic performance.

\section{DAD concept for precast wall panels}

Figure 1 presents the conceptual design of a prototype warehouse or industrial building where it is envisaged precast hollow core wall units would be used as the principal structural and cladding elements. The "seismic walls" carry gravity and wind loads from the roof where rafters are seated on top of these structural elements. Infill panels are used between the "seismic walls" which are referred to as "non-seismic wall panels". The latter are principally designed to act as cladding panels; they are only required to sustain their self-weight and wind face-loads. The tributary area from roof loading is designed to be carried by the seismic wall panels. Resistance of lateral wind and seismic forces is via a longitudinal "wind truss" system that acts through a roof diaphragm. This research seeks to design, construct and test a subassembly "seismic wall" panel under biaxial lateral cyclic loading. The "seismic wall" is designed and detailed according to the DAD (Damage Avoidance Design) principles proposed by researchers [12-14] where the bottom of the wall is protected with steelarmouring. 


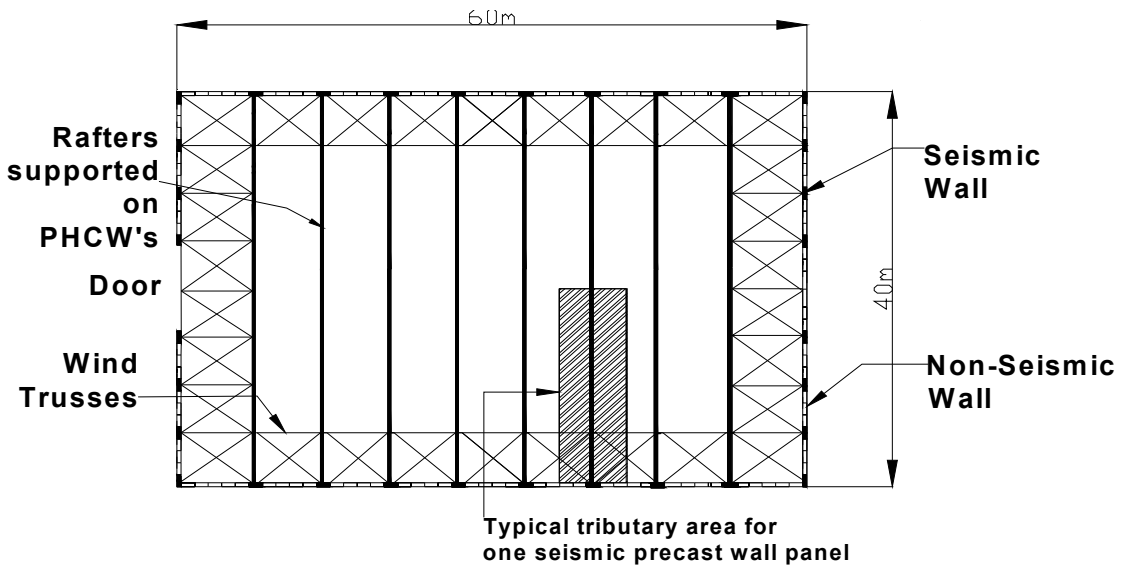

Figure 1: Layout of a building consists of seismic and non-seismic precast hollow core walls along the perimeter of the structure.

\section{Experimental program}

Figure 2 presents the details of the two wall specimens including location of unbonded tendons, types of energy dissipators and instrumentation. Wall 1 was designed with a pair of bonded fuse-bars and Wall 2 was designed with two replaceable energy dissipators which were unbonded fuse-bars and steel mechanical energy dissipators. The panels dimensions of Wall 1 and Wall 2 were identical with an effective height of $3000 \mathrm{~mm}$, width of $1200 \mathrm{~mm}$, thickness of $b^{w} 200 \mathrm{~mm}$, aspect ratio of $A_{r}=H / B=2.33$ and slenderness ratio of $\lambda=$ $\mathrm{H} / \mathrm{b}_{\mathrm{w}}=14$.

Figure 2(a) shows the location of bonded fuse-bars at the two-middle void sections of Wall 1. The bonded fuse-bars were cast into the foundation beam and the extruded parts were screwed using nuts $(\mathrm{RB} 25 \mathrm{~N})$ from the steel channel before pouring the concrete. Two thread-bars (RB25) were used as unbonded tendons which were located at the second and fifth voids of the hollow section. To represent the gravity load reaction from the roof and cladding, a mass concrete block, with a self-weight of $34 \mathrm{kN}$, was placed on top of Wall 1. Figure 2(b) presents Wall 2 with two combinations of unbonded tendons and two types of energy dissipators (unbonded fuse-bars and mechanical energy dissipator). Unbonded fuse-bars were joined to the thread bars (RB25) using couplers at two-thirds height and screwed to the couplers embedded inside the foundation beam. This class of energy dissipator can be replaced or re-prestressed if fusebars undergo significant strain well into the strain-hardening region. The dissipators were designed to give similar equivalent viscous damping and base moment contribution to the system employed in Wall 1. The unbonded fuse-bars and unbonded tendons were prestressed at different levels before being tested under various biaxial displacement patterns. 


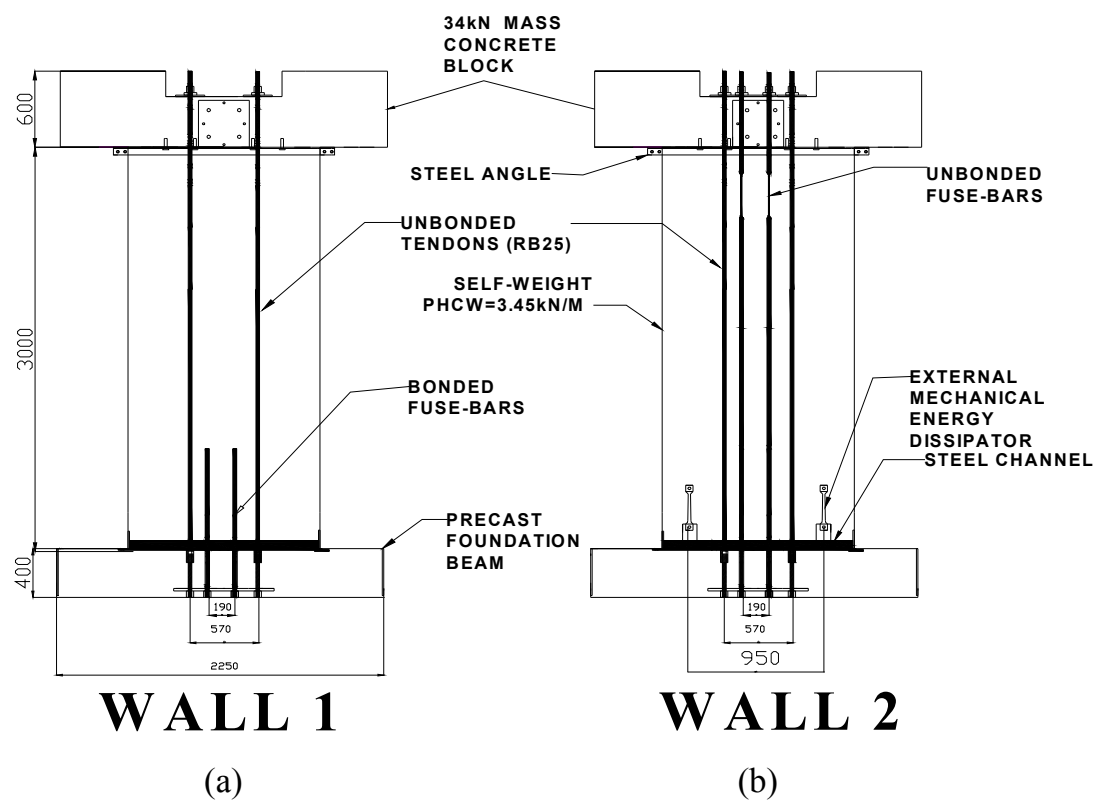

Figure 2: $\quad$ Specimens used for experimental work; (a) Wall 1 with bonded fuse-bars, and (b) Wall 2 with unbounded fuse-bar and mechanical energy dissipators.

Walls 1 and 2 were loaded separately in-plane and out-of-plane under increasing drift amplitudes up to $\pm 2.0 \%$. The specimens were also loaded bilaterally, that is under concurrent in-plane and out-of-plane displacements. Two bi-lateral loading patterns were developed and are referred to herein as "4-leaf clover" and "double 4-leaf clover" patterns. Each specimen was cycled in displacement control using two completely reversed sinusoidal cycles to drift amplitudes of $0.1 \%, 0.5 \%, 1.0 \%, 1.5 \%$ and $2.0 \%$.

\subsection{Experimental results for Wall 1}

Figure 3 presents the overall experimental results of the seismic bi-lateral performance of Wall 1 at $\pm 1.5 \%$ drifts amplitude under the "4-leaf clover" displacement pattern. The initial level of prestress applied (20\% of yield) was insufficient to overcome the compression capacity of the centrally located unbonded fuse-bars, so the test was repeated at a prestress level of $64 \%$ of yield, the results of which are presented herein. Figure 3(a) presents the experimentally observed bi-lateral "4-leaf clover" displacement pattern applied to the wall specimen. This pattern was chosen to examine the extreme seismic behaviour when the out-of-plane loading reached maximum drift while zero drift at inplane directions or vice-versa. Interaction between in-plane and out-of-plane movement where the wall tends to rock on a corner, rather than an edge could also be observed. No ill-effects from this interaction were detects at the corners 
of the wall base. Figure 3(b) presents the in-plane force-displacement response to the applied displacements. From these results it is evident that the first cycle of loading to a new target peak displacement significant energy is dissipated. On unloading, re-centering occurs. But due to yielding of the fuses during the previous maximum cycle, little energy is dissipated in the second and subsequent cycles.

Figure 3(c) shows the experimental and theoretical results for out-of-plane behaviour. The theoretical results show that an elastic response is expected outof-plane, but some non-linear response is evident. It should be noted, however, that the out-of-plane forces are only some $10 \%$ of the in-plane forces; most of the energy absorbed is attributed to some friction in the fittings, hinge and swivels of the experimental apparatus. Figure 3(d) shows the out-of-plane behaviour for Wall 1 with two unbonded tendons and a couple of bonded fusebars located at the center in N-S direction together with its hysteresis loops.
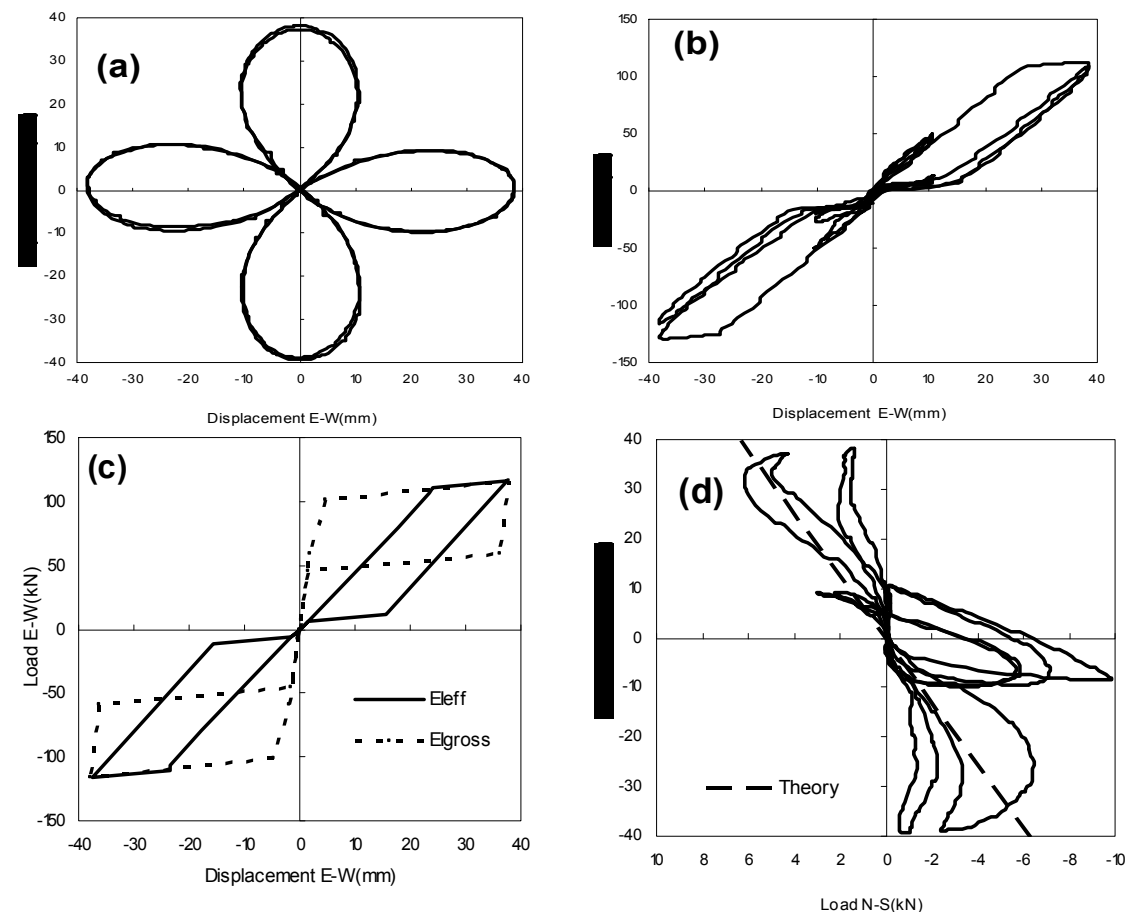

Figure 3: $\quad$ Experimental results of Wall 1 under biaxial lateral cyclic loading; (a) "4-leaf clover" pattern; (b) hysteresis loops in-plane (E-W direction); (c) flag-shape behaviour; and (d) hysteresis loops for out-of-plane (N-S direction).

\subsection{Experimental results for Wall 2}

This section presents the experimental results for specimen Wall 2. The specimen was tested with different combinations of prestress (using unbonded 
tendons and fuse-bars), and without and with supplementary mechanical energy dissipating devices.

\subsubsection{Wall 2 with unbonded fuse-bars}

Figure 4 presents the experimental results for Wall 2 when tested with a pair of unbonded tendons plus unbonded fuse-bars. This specimen was tested at four drift levels $( \pm 0.1 \%, \pm 0.5 \%, \pm 1.0 \%$ and $\pm 1.5 \%)$ using the "double 4-leaf clover" displacement pattern shown in Fig. 4(a). The unbonded fuse-bars were prestressed to $50 \%$ of their yield capacity. For the lower drift amplitude $( \pm 0.1 \%$, $\pm 0.5 \%$ and $\pm 1.0 \%$ ) the wall remained "mostly elastic", whereas nonlinear "flagshape" behavior occurred at $1.5 \%$ drift amplitudes when the main tendons yielded. For the latter, the unbonded tendons remained in the elastic region but the fuse-bars yielded and dissipated most of the energy as shown in Fig. 4(b).

Figure 4(c) shows the experimental and theoretical results for out-of-plane behaviour for wall panel with unbonded fuse-bars. The theoretical results show that there is a linear response for out-of-plane direction. Again, the experimental
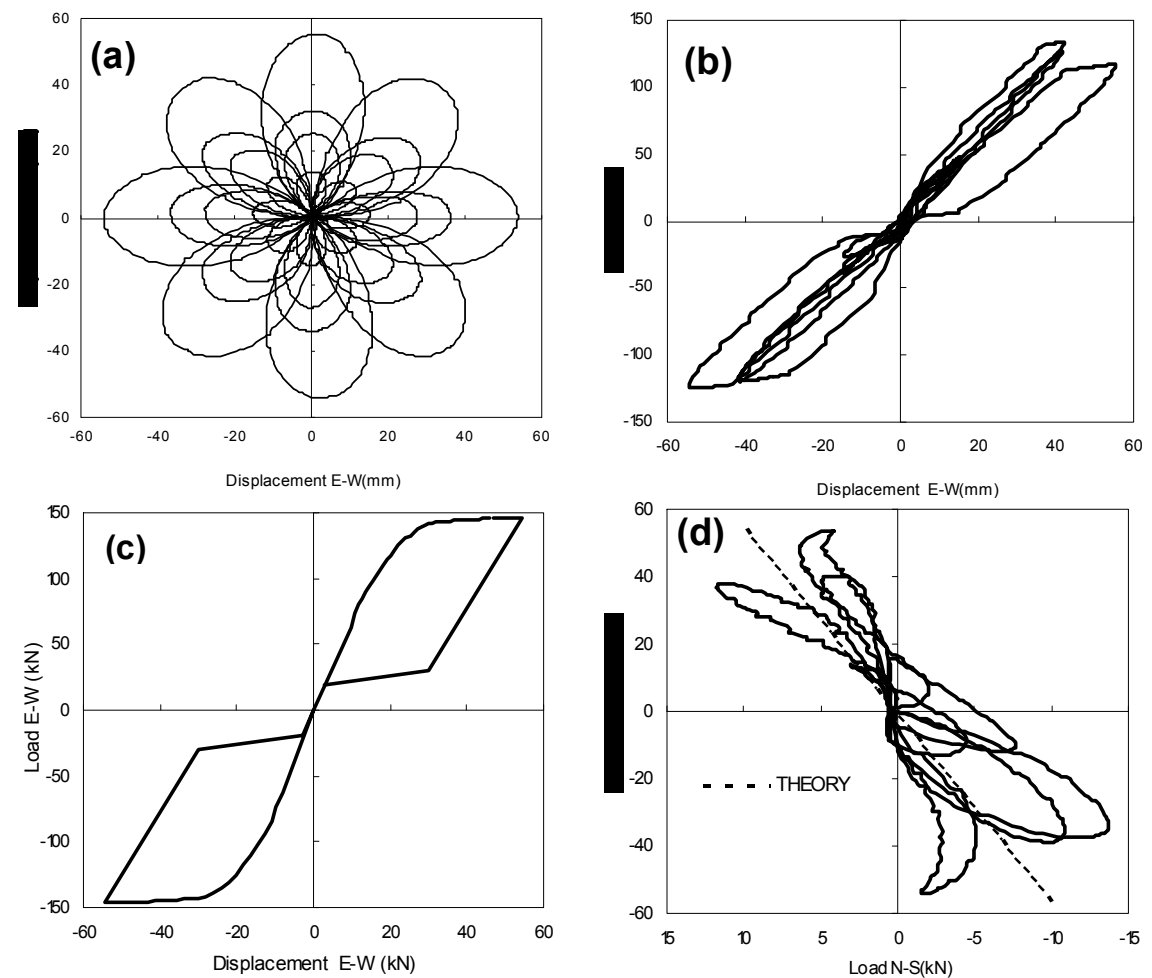

Figure 4: Experimental results of Wall 2 with unbounded tendon and fusebars; (a) double 4-leaf clover" pattern of displacement control; (b) hysteresis loops in-plane (E-W direction); (c) theoretical flagshape behaviour (E-W direction); and (d) hysteresis loops for outof-plane (N-S direction). 
result in out-of-plane direction shows some $\pm 5 \mathrm{kN}$ deviation from the expected elastic line. This force level, which is less than $5 \%$ of the compression in-plane levels of lateral force, is evidence of friction in the fittings of the experimental apparatus. Figure 4(d) shows the out-of-plane behavior of Wall 2 in N-S direction.

\subsubsection{Wall 2 with mechanical energy dissipators}

Figure 5 presents the overall experimental performance of Wall 2 which had an initial prestress equal to $50 \%$ of the unbonded tendon yield force plus four external steel mechanical energy dissipators. The external energy dissipators were prefabricated and welded to a steel angle at the foundation. The specimen was tested using the "double 4-leaf clover" pattern up to $1.5 \%$ drift as shown in Figure 5(a). Figure 5(b) and 5(c) show the in-plane and out-of-plane force response to the applied displacement pattern, respectively. A modest amount of
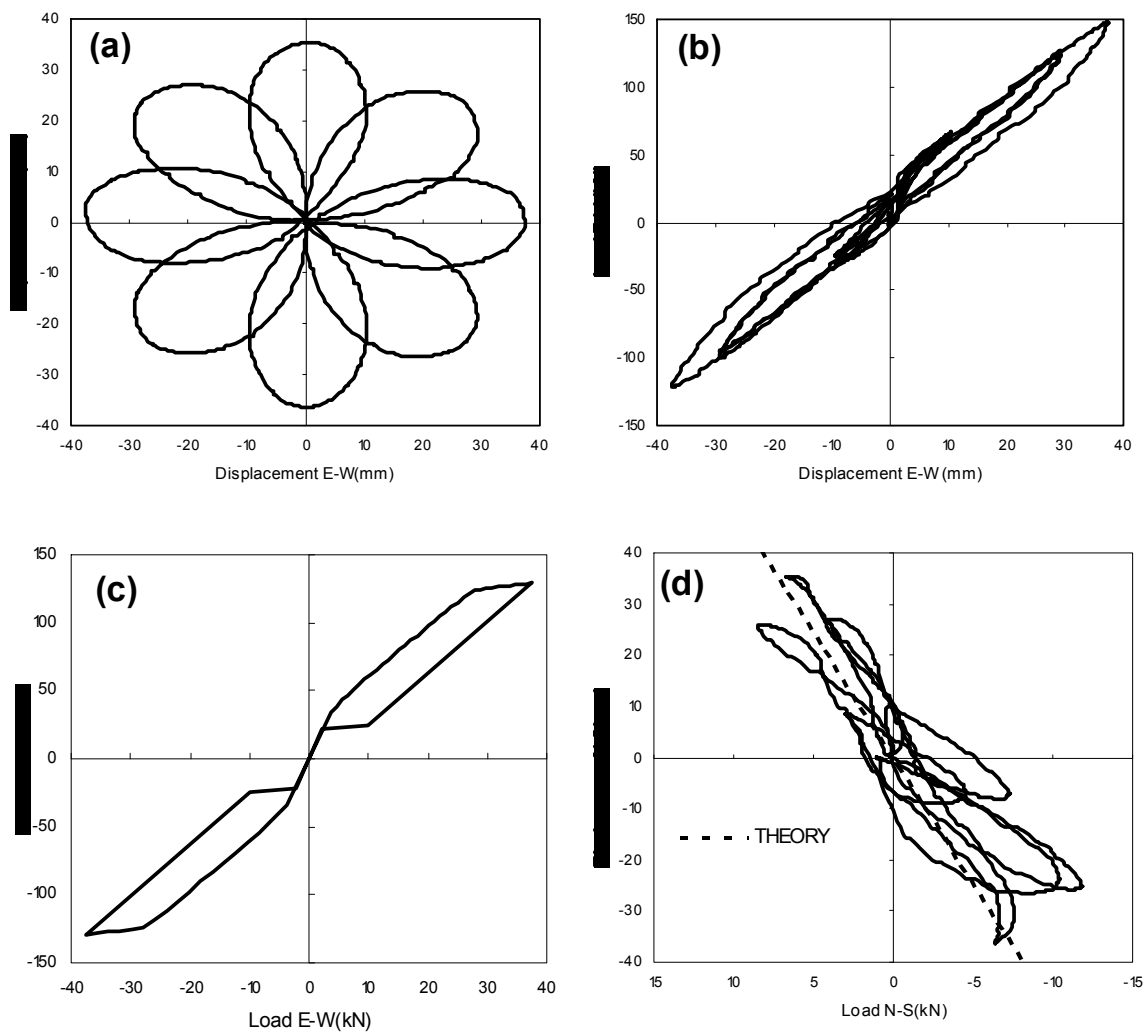

Figure 5: Experimental results for Wall 2 with tendons and mechanical energy dissipators; (a) double 4-leaf clover" pattern; (b) hysteresis loops in-plane (E-W direction); (c) theoretical flag-shape behaviour (E-W direction); and (d) hysteresis loops for out-of-plane (N-S direction). 
in-plane hysteretic performance is evident. Results show that the specimen maintained its self-centering capability with only a small value of residual displacement recorded during unloading. It should be noted that eventual buckling of the mechanical energy dissipator devices at the $1.5 \%$ drift amplitude led to some minor $(5 \mathrm{~mm})$ residual displacement. Figure 5(d) shows out-of-plane behavior for Wall 2 which consists two unbonded tendons and four external mechanical energy dissipators which were placed on the outside of the wall in $\mathrm{N}$ $\mathrm{S}$ direction.

\section{Effective damping}

The theoretical equivalent viscous damping for a system with hysteretic behavior is calculated using the following [15]:

$$
\xi_{e q}=\frac{1}{4 \pi} \frac{E_{D}}{E_{S O}}=\frac{1}{2 \pi} \frac{E_{D}}{F_{\max } \Delta_{\max }}
$$

where $E_{D}=$ dissipated energy resulting from hysteretic performance; $E_{S O}=1 / 2\left(F_{\max } \Delta_{\max }\right)$ strain energy; $F_{\max }=$ average maximum strength in forward and reverse loading directions; and $\Delta_{\max }=$ average maximum displacements in both loading directions.

Figure 6 presents the experimentally inferred equivalent viscous damping for the three different types of energy dissipators namely bonded fuse-bars (see Fig. 6(a) and (d), unbonded fuse-bars (see Fig. 6(b) and (e)) and external energy dissipators (see Fig 6(c) and (f)). The experimental values of equivalent viscous damping using these type of energy dissipators for the first and second cycles at $0.1 \%, 0.5 \%, 1 \%, 1.5 \%$ and $1.75 \%$ drift. The equivalent viscous damping tends to increase as the drift increases and the first cycle has higher equivalent viscous damping as compared to second cycle. Similar patterns of equivalent viscous damping for the wall panel using unbonded fuse-bars and external mechanical energy dissipators were observed. Therefore, it is suggested that for design purposes, additional damping in the order of $10 \%$ can be added to the usual $5 \%$ damping, giving a total of $15 \%$ effective damping.

\section{Discussion}

Unbonded fuse-bars are generally recommended because the wall remains fully clamped to the base plate and does not "sit-up" on the energy dissipators as is the case for bonded fuse-bars and mechanical energy dissipators. Following an earthquake, if these energy dissipators yield and the wall tends to "sit-up" on those energy dissipators after a large cycle of loading, the system is permanently softened. Thus, it is recommended that in accordance with the DAD philosophy, post-tensioned tendons with $50 \%$ prestress and in-series unbonded fuse-bars are adequate for satisfactory seismic behavior. In rare seismic events, the fuse-bars 

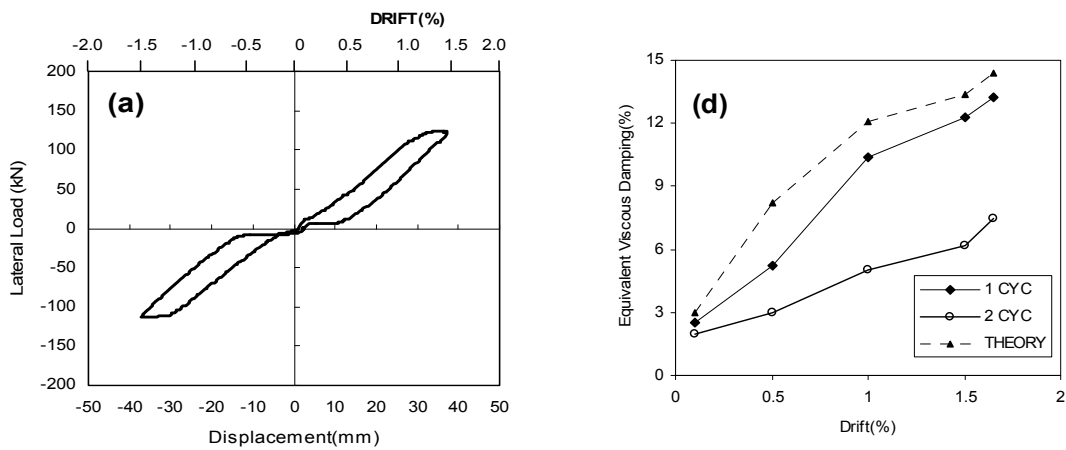

DRIFT(\%)
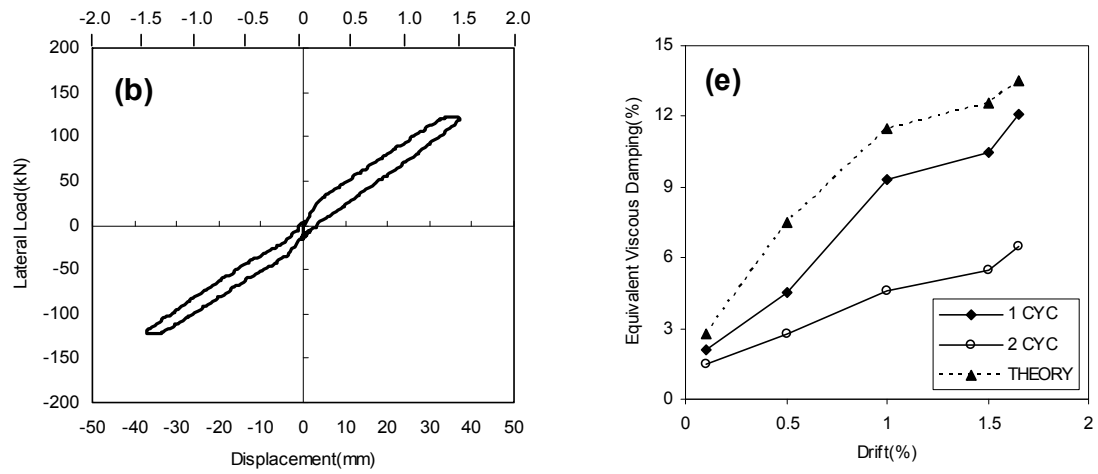

DRIFT(\%)
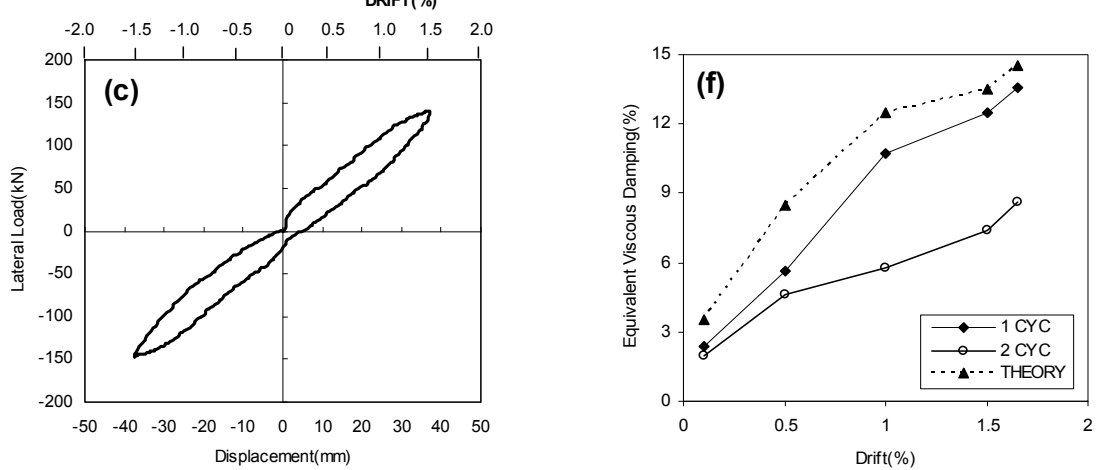

Figure 6: A comparative performance using three different types of energy dissipators; (a) bonded fuse-bars; (b) unbonded fuse-bars; (c) mechanical energy dissipators; (d) equivalent viscous damping using bonded fuse-bars; (e) equivalent viscous damping using unbonded fuse-bars; and (f) equivalent viscous damping using external energy dissipators. 
may be expected to yield, but in the anchorage zones, wall toes and other parts of the structure are "damage protected". For very rare seismic events where substantial fuse-bar yielding may occur, following an earthquake the fuses can be removed, replaced, and the tendons re-stressed. It is also to be noted that by providing pintles or shear keys at the bottom corners of walls, the seismic lateral base shear can be resisted by rocking without sliding. No transverse reinforcement in precast hollow core walls needs to be used. In this study, to help improve shear resistance at the base of the wall the hollow core voids were filled to a height equivalent to one unit width $(1.2 \mathrm{~m})$.

\section{Conclusions}

Based on the experimental study of bi-laterally loaded rocking precast prestressed concrete hollow core wall units presented herein, the following conclusions are drawn:

1) The experiments have demonstrated that precast prestress concrete hollow core units can be used as a viable alternative to solid reinforced concrete walls. This is in spite of the lack of any transverse reinforcement for shear resistance. This gives a wider scope for the use of hollow core units which have customarily been used mostly for floor units in buildings.

2) The success of the rocking hollow core walls is attributed to the Damage Avoidance Design (DAD) approach that requires carefully detailed armouring at the base of the wall to enable high point load stresses to be dispersed up the wall and also into the foundation.

3) Rocking walls in themselves dissipate little energy, but this can be improved through the use of supplementary energy dissipators. Of the dissipators tested in this study each had advantages and disadvantages. It would appear that the best trade-off is to use prestressed fuse-bars only. Such as arrangement always keeps the wall clamped firmly to the foundation when not rocking. Other dissipator types can cause the walls to "sit up" on the devices when they yield, this effectively softens the structure. For the type of dissipators studied, it is suggested that $10 \%$ equivalent viscous damping can be added to the usual 5\% intrinsic damping to give a total of $15 \%$ effective viscous damping for design purposes.

\section{Acknowledgements}

The authors would like to thank FRGS (Fundamental Research Grant Scheme) from Ministry of Higher Education and the Research Management Institute, University Teknologi MARA, Malaysia for the funding this research work. In addition, the authors also want to express their gratitude to the technicians Laboratory and postgraduate students from Faculty of Civil Engineering for their contribution, participation and commitment in conducting this experimental work successfully. 


\section{References}

[1] Fintel, M. (1995). "Performance of buildings with shear walls in earthquakes in the last thirty years." PCI Journal, 40(3), 62-80.

[2] Berg, G.V. and Stratta, J.L. (1964). "Anchorage and the Alaska Earthquake on March 27, 1964." American Iron and Steel Institute, 52-63.

[3] Wyllie, L.A. and Filson, J.R. (1989). "Armenia Earthquake reconnaissance report.” Earthquake Spectra, Special Supplement, August 1989.

[4] Iverson, J.K. and Hawkins, N.M. (1994). "Performance of precast /prestressing building structures during Northridge Earthquake." PCI Journal, 36(2), 38-55.

[5] Youd, T.L., Bardet, J.P., Bray, J.D. (2000). “Kocaeli, Turkey, Earthquake of August 17, 1999 reconnaissance report." Earthquake Spectra, Supplement A to Volume 6, December 2000.

[6] Ghosh, S.K. (2001). "Observations from the Bhuj Earthquake of January 16, 2001.” PCI Journal, 46(2), 34-42.

[7] Housner, G.W. (1963). "The behaviour of inverted pendulum structures during earthquake." Bulletin of the Seismological Society of America, 53(2), 403-417.

[8] Meek, J.W. (1978). "Effects of foundation tipping on dynamic response." Journal of Structural Engineering, ASCE, 101(7), 1297-1311.

[9] Yim, C.S., Chopra, A.K. and Penzien, J. (1980). "Rocking response of rigid blocks to earthquake." Earthquake Engineering and Structural Dynamics, 8, 565-587.

[10] Aslam, M., Goddon, W.G. and Scalise, D.T. (1980). "Earthquake rocking response of rigid bodies." Journal of Structural Engineering, ASCE, 106 (2), 377-392.

[11] Priestley, M.J.N. and MacRae, G.A. (1996). "Seismic testing of precast beam-to-column joint assemblage with unbonded tendons." PCI Journal, 41(1), 64-80.

[12] Hamid, N.H. (2006). "Seismic damage avoidance design of warehouse buildings constructed using precast hollow core panels." PhD thesis, University of Canterbury, Christchurch, New Zealand.

[13] Holden, T.J., Restrepo, J. and Mander, J.B. (2003). "Seismic performance of precast reinforced and prestressed concrete walls." Journal of Structural Engineering, ASCE, 129(3), 286-296.

[14] Mander, J.B. and Cheng, C.T. (1997). "Seismic resistance of piers based on damage avoidance design." Technical Report NCEER-97-0014, National Center for Earthquake Engineering Research, State University of New York at Buffalo, Department of Civil, Structural and Environmental Engineering, Buffalo, New York, U.S.A.

[15] Chopra, A.L. (2001). Dynamic of Structures: Theory and Application to Earthquake Engineering. Second Edition, Prentice Hall, Upper Saddle River, New Jersey, U.S.A. 